SECTION 31. Economic research, finance, innovation.

Balynin Igor Victorovich

student of the 4th course, Financial and Accounting Department, Financial University under the Government of the Russian Federation (Kaluga Branch)

\title{
EVALUATION OF THE DEBT POLICY REGIONS OF PRIVOLZHSKY FEDERAL DISTRICT RUSSIAN FEDERATION IN TERMS OF IMBALANCE REGIONAL BUDGETS
}

\begin{abstract}
In scientific article determines problem of the imbalance of regional budgets are available in economics approaches to achieve it in the context of world historical development, as well as evaluated the impact on the level of risk of an imbalance of regional budgets based on of the developed model and highlight the principles of public debt management.

Key words: public debt in the region, imbalance of regional budgets, the risk of imbalance of regional budgets.

\section{ОЦЕНКА ДОЛГОВОЙ ПОЛИТИКИ СУБЬЕКТОВ ПРИВОЛЖСКОГО ФЕДЕРАЛЬНОГО ОКРУГА РОССИЙСКОЙ ФЕДЕРАЦИИ В УСЛОВИЯХ НЕСБАЛАНСИРОВАННОСТИ РЕГИОНАЛЬНЫХ БЮДЖЕТОВ}

Аннотация: В научной статье обозначена проблема несбалансированности региональных бюджетов, подходы $\kappa$ ее достижению в контексте мирового исторического развития, а также произведена оченка влияния долговой политики региона на уровень риска несбалансированности региональных бюджетов на основе разработанной модели и выделены принщипы управления государственным долгом.

Ключевые слова: госдолг региона, несбалансированность региональных бюджетов, риск несбалансированности региональных бюджетов.

Одним из ключевых вызовов бюджетной политики Российской Федерации в настоящее время является проблема несбалансированности и обеспечения устойчивости региональных бюджетов. В Российской Федерации понятие сбалансированности закреплено в тридцать третьей статье пятой главы Бюджетного Кодекса Российской Федерации (далее-БК РФ), устанавливающей принцип сбалансированности бюджета.

В последнее время необходимость и важность решения проблемы сбалансированности, создания условий для устойчивости и стабильности бюджетов бюджетной системы Российской Федерации, устранения рисков их несбалансированности постоянно декларируются в Бюджетных Посланиях Президента Российской Федерации, которые, как известно, определяют бюджетную политику на ближайшие три года. Проблема сбалансированности бюджетов бюджетной системы обозначена и в государственной программе «Управление государственными финансами», опубликованной на сайте Минфина России в марте 2013 года. В ней в качестве обозначенной цели является долгосрочная сбалансированность и устойчивость бюджетов бюджетной системы РФ, создание инструментов долгосрочного планирования и другие вопросы. Нельзя не отметить, что в конце июля 2013 года произошли некоторые изменения в разделе 4 БК РФ «Сбалансированность бюджета», связанные с главой 13, которая законодательно регулирует вопросы дефицита бюджетов, а также источников их финансирования. 
Следует отметить, что о необходимости оказания помощи субъектам в решении проблемы несбалансированности региональных бюджетов говорил и председатель Правительства Российской Федерации Д.А. Медведев на совещании с вицепремьерами, которое проходило 07 октября 2013 года.

В целях выявления субъектов с наибольшим и наименьшим уровнем риска несбалансированности бюджета была предложена авторская модель оценки, базирующаяся на нескольких группах факторов [1]. Одной из составляющих разработанной модели является оценка долговой политики региона. Для этого необходимо рассчитать следующие показатели:

1) Темп роста (снижения) государственного долга субъекта;

2) Отношение государственного долга региона к ВРП;

3) Величина государственного долга субъекта на душу населения.

После выполнения вышеперечисленных расчётов необходимо осуществлять построение рейтинга по каждому из вышеперечисленных показателей с определением промежуточного среднего рейтингового балла. В таблице 1 представлена динамика государственного долга субъектов РФ Приволжского федерального округа.

Таблица 1

Динамика государственного долга субъектов РФ Приволжского федерального округа, в \% к предыдущему году

\begin{tabular}{|l|l|l|l|l|l|}
\hline \multicolumn{1}{|c|}{ Субъект РФ } & \multicolumn{1}{c|}{$\mathbf{2 0 0 8}$} & \multicolumn{1}{c|}{$\mathbf{2 0 0 9}$} & \multicolumn{1}{c|}{$\mathbf{2 0 1 0}$} & \multicolumn{1}{c|}{$\mathbf{2 0 1 1}$} & \multicolumn{1}{c|}{$\mathbf{2 0 1 2}$} \\
\hline Республика Башкортостан & 93,13 & 182,58 & 146,67 & 113,68 & 119,82 \\
\hline Республика Марий Эл & 134,92 & 133,77 & 162,40 & 130,05 & 128,54 \\
\hline Республика Мордовия & 183,51 & 139,27 & 217,01 & 162,24 & 122,38 \\
\hline Республика Татарстан & 127,78 & 162,56 & 157,70 & 138,85 & 106,96 \\
\hline Удмуртская Республика & 96,81 & 192,88 & 167,25 & 110,59 & 123,56 \\
\hline Чувашская Республика & 152,52 & 101,71 & 121,14 & 90,62 & 112,79 \\
\hline Пермский край & 48,59 & 460,29 & 217,81 & 94,39 & 59,88 \\
\hline Кировская область & 182,00 & 172,62 & 135,45 & 117,49 & 130,81 \\
\hline Нижегородская область & 116,55 & 258,60 & 136,37 & 141,71 & 120,62 \\
\hline Оренбургская область & 106,61 & 103,42 & 132,62 & 104,31 & 144,22 \\
\hline Пензенская область & 151,26 & 131,66 & 111,29 & 176,83 & 127,34 \\
\hline Самарская область & 158,92 & 110,38 & 101,72 & 133,80 & 108,81 \\
\hline Саратовская область & 151,93 & 152,82 & 148,34 & 132,72 & 124,37 \\
\hline Ульяновская область & 1845,78 & 189,61 & 130,48 & 189,82 & 170,26 \\
\hline
\end{tabular}

Источник: рассчитано автором на основании данных [4]

Анализ таблицы 1 выявил наличие роста государственного долга практически во всех регионах в течение всего исследуемого периода (за исключением республики Башкортостан (в 2008 году), Удмуртской республики (в 2008 году), Чувашской республики (в 2011 году), Пермского края (в 2008, 2011, 2012 годах)).В таблице 2 представлены рассчитанные значения показателя «отношение государственного долга региона к валовому региональному продукту».

Таблица 2

Отношение государственного долга регионов Приволжского федерального округа к валовому региональному продукту, в \%

\begin{tabular}{|l|l|l|l|l|l|}
\hline \multicolumn{1}{|c|}{ Субъект РФ } & \multicolumn{1}{c|}{$\mathbf{2 0 0 8}$} & \multicolumn{1}{c|}{$\mathbf{2 0 0 9}$} & \multicolumn{1}{c|}{$\mathbf{2 0 1 0}$} & \multicolumn{1}{c|}{$\mathbf{2 0 1 1}$} & \multicolumn{1}{c|}{$\mathbf{2 0 1 2}$} \\
\hline Республика Башкортостан & 0,51 & 1,07 & 1,34 & 1,21 & 1,30 \\
\hline Республика Марий Эл & 3,17 & 4,03 & 5,50 & 6,11 & 7,14 \\
\hline Республика Мордовия & 4,30 & 6,19 & 11,59 & 15,62 & 17,57 \\
\hline Республика Татарстан & 2,44 & 4,14 & 5,77 & 6,29 & 5,92 \\
\hline Удмуртская Республика & 1,63 & 3,30 & 4,65 & 4,21 & 5,04 \\
\hline Чувашская Республика & 5,23 & 5,89 & 6,33 & 4,81 & 4,74 \\
\hline
\end{tabular}




\begin{tabular}{|l|l|l|l|l|l|} 
Пермский край & 0,02 & 0,08 & 0,16 & 0,11 & 0,04 \\
\hline Кировская область & 2,44 & 4,35 & 5,01 & 5,01 & 6,20 \\
\hline Нижегородская область & 1,29 & 3,59 & 4,10 & 4,93 & 5,66 \\
\hline Оренбургская область & 1,67 & 1,80 & 2,15 & 1,86 & 2,54 \\
\hline Пензенская область & 2,78 & 3,67 & 3,49 & 5,32 & 6,61 \\
\hline Самарская область & 3,22 & 4,26 & 3,64 & 4,06 & 4,03 \\
\hline Саратовская область & 3,15 & 4,74 & 6,11 & 7,14 & 8,14 \\
\hline Ульяновская область & 0,73 & 1,36 & 1,54 & 2,33 & 3,69 \\
\hline
\end{tabular}

Источник: рассчитано автором на основании данных [4] и [5]

Анализ данных таблицы 2 выявил, что наибольшие значения данного показателя характеризуют Чувашскую республику (в 2008 г.), а также республику Мордовию (2009-2012 гг.).

В таблице 3 представлены рассчитанные значения государственного долга соответствующего субъекта на душу населения.

Таблица 3

Государственный долг регионов Приволжского федерального округа на душу населения, в тыс. рублей

\begin{tabular}{|l|l|l|l|l|l|}
\hline \multicolumn{1}{|c|}{ Субъект РФ } & \multicolumn{1}{|c|}{$\mathbf{2 0 0 8}$} & \multicolumn{1}{|c|}{$\mathbf{2 0 0 9}$} & \multicolumn{1}{c|}{$\mathbf{2 0 1 0}$} & \multicolumn{1}{c|}{$\mathbf{2 0 1 1}$} & \multicolumn{1}{c|}{$\mathbf{2 0 1 2}$} \\
\hline Республика Башкортостан & 0,9345 & 1,7026 & 2,4934 & 2,8399 & 3,4056 \\
\hline Республика Марий Эл & 2,9801 & 3,9978 & 6,5177 & 8,5134 & 10,9760 \\
\hline Республика Мордовия & 4,8508 & 6,8091 & 14,6572 & 24,0041 & 29,6224 \\
\hline Республика Татарстан & 5,9836 & 9,7017 & 15,2631 & 21,1050 & 22,4635 \\
\hline Удмуртская Республика & 2,5877 & 4,9983 & 8,3920 & 9,2952 & 11,4884 \\
\hline Чувашская Республика & 6,3364 & 6,4500 & 7,9874 & 7,2584 & 8,2100 \\
\hline Пермский край & 0,0359 & 0,1658 & 0,3704 & 0,3499 & 0,2093 \\
\hline Кировская область & 2,6337 & 4,5796 & 6,4453 & 7,6344 & 10,0532 \\
\hline Нижегородская область & 2,2728 & 5,9077 & 8,0950 & 11,5089 & 13,9115 \\
\hline Оренбургская область & 3,4033 & 3,5173 & 4,8515 & 5,0802 & 7,3540 \\
\hline Пензенская область & 2,9743 & 3,9350 & 4,3452 & 7,7254 & 9,8942 \\
\hline Самарская область & 7,1038 & 7,8442 & 7,8669 & 10,5302 & 11,4606 \\
\hline Саратовская область & 3,9385 & 6,0376 & 9,1182 & 12,1520 & 15,1459 \\
\hline Ульяновская область & 0,8483 & 1,6165 & 2,1223 & 4,0549 & 6,9453 \\
\hline
\end{tabular}

Источник: рассчитано автором на основании данных [4] и [5]

По данным, представленным в таблице 3, следует вывод, что наибольшие значения долга на душу населения в Самарской области (в 2008 г.), в республике Татарстан (в 2009 и 2010 гг.), в республике Мордовия (в 2011 и 2012 гг.). На основе произведенных расчетов, результаты которых представлены в таблицах 1-3, были рассчитаны рейтинговые баллы по каждому субъекту и каждому показателю, промежуточный средний рейтинговый балл и был построен промежуточный рейтинг субъектов РФ Приволжского федерального округа, который представлен в таблице 4.

Таблица 4

Промежуточный рейтинг субъектов РФ Приволжского федерального округа по результатам оценки влияния долговой политики на уровень риска несбалансированности региональных бюджетов

\begin{tabular}{|l|c|c|c|c|c|c|}
\hline \multirow{2}{*}{\multicolumn{1}{|c|}{ Субъект РФ }} & \multicolumn{7}{c|}{ СРБ } \\
\cline { 2 - 7 } & $\mathbf{2 0 0 8}$ & $\mathbf{2 0 0 9}$ & $\mathbf{2 0 1 0}$ & $\mathbf{2 0 1 1}$ & $\mathbf{2 0 1 2}$ & ПСРБ \\
\hline Пермский край & 1,0000 & 5,3333 & 5,3333 & 1,3333 & 1,0000 & 2,8000 \\
\hline Республика Башкортостан & 2,3333 & 5,0000 & 4,3333 & 3,0000 & 3,0000 & 3,5333 \\
\hline Оренбургская область & 6,3333 & 3,3333 & 4,6667 & 3,3333 & 6,6667 & 4,8667 \\
\hline Ульяновская область & 6,3333 & 5,3333 & 3,0000 & 7,0000 & 7,0000 & 5,7333 \\
\hline Пензенская область & 8,0000 & 5,3333 & 3,6667 & 10,0000 & 9,0000 & 7,2000 \\
\hline
\end{tabular}




\begin{tabular}{|l|l|l|l|l|l|l|} 
Удмуртская Республика & 4,3333 & 8,3333 & 10,3333 & 6,3333 & 8,3333 & 7,5333 \\
\hline Чувашская Республика & 12,3333 & 8,3333 & 8,3333 & 4,3333 & 5,0000 & 7,6667 \\
\hline Самарская область & 12,3333 & 8,6667 & 5,0000 & 8,0000 & 5,6667 & 7,9333 \\
\hline Нижегородская область & 4,3333 & 9,3333 & 8,0000 & 10,0000 & 8,3333 & 8,0000 \\
\hline Кировская область & 8,6667 & 9,0000 & 7,0000 & 7,0000 & 9,6667 & 8,2667 \\
\hline Республика Марий Эл & 8,6667 & 6,3333 & 9,3333 & 8,6667 & 10,3333 & 8,6667 \\
\hline Республика Татарстан & 8,3333 & 10,3333 & 11,6667 & 11,6667 & 8,0000 & 10,0000 \\
\hline Саратовская область & 9,6667 & 9,6667 & 11,0000 & 11,0000 & 11,3333 & 10,5333 \\
\hline Республика Мордовия & 12,3333 & 10,6667 & 13,3333 & 13,3333 & 11,6667 & 12,2667 \\
\hline
\end{tabular}

Источник: рассчитано автором на основании таблиц 1-3

Анализ таблицы 4 позволяет сделать вывод о том, что наибольшее влияние долговой политики на уровень риска несбалансированности региональных бюджетов испытывают Саратовская область (10,5333 баллов), республика Мордовия (12,2667 баллов), наименьшее - Пермский край (2,8000 баллов) и республика Башкортостан (3,5333 баллов).В основу управления государственным долгом должны быть положены принципы безусловности, срочности, согласованности, снижения рисков, оптимальности, гласности, а также единой долговой политики.

По результатам проведенного исследования необходимо сделать следующие выводы:

1. Практически во всех регионах Приволжского федерального округа был зафиксирован ежегодный рост государственного долга субъекта, в некоторых достаточно значительный.

2. Результаты расчета отношений государственного долга к валовому региональному продукту позволяют сделать вывод о наибольшем значении этого показателя в в Самарской области (в 2008 г.), в республике Татарстан (в 2009 и 2010 гг.), в республике Мордовия (в 2011 и 2012 гг.).

3. Наибольшие значения государственного долга на душу населения зафиксированы в Самарской области (в 2008 г.), в республике Татарстан (в 2009 и 2010 гг.), в республике Мордовия (в 2011 и 2012 гг.).

Таким образом, наибольшее влияние долговой политики на уровень риска несбалансированности региональных бюджетов характерно для республики Мордовии и Самарской области среди субъектов Российской Федерации Приволжского федерального округа.

\section{Литература}

1. Balynin I.V. Debt policy of regions of the Central federal district in 2008-2012: an analysis, evaluation data and effect on the level of risk of imbalance regional budgets//The strategies of Modern Science Development: Proceedings of the III International scientificpractical conference (Yelm, WA, USA, 12-13 September 2013). - Yelm, WA, USA: Science Book Publishing House, 2013. - 176 p., p. 35-41.

2. Balynin I. V. The problem of the imbalance of regional budgets: an essential characteristic and complex multifactorial risk assessment model // 5th International Scientific Conference "European Applied Sciences: modern approaches in scientific researches": Papers of the 5th International Scientific Conference.August 26-27,2013,Stuttgart, Germany.166 p., p.121-122. 3. Министерство финансов. - [Электронный ресурс]. - Режим доступа: http://minfin.ru (дата обращения 30.11.2013)

4. Федеральная служба государственной статистики. - [Электронный ресурс]. - Режим доступа: http://www.gks.ru/wps/wcm/connect/rosstat_main/rosstat/ru/ (дата обращения 30.11.2013) 